\title{
Article \\ pH-Responsive Self-Assembly of Designer Aromatic Peptide Amphiphiles and Enzymatic Post-Modification of Assembled Structures
}

\author{
Rie Wakabayashi ${ }^{1, *,+}(\mathbb{D})$, Ayato Higuchi ${ }^{1,+}{ }^{\text {, Hiroki Obayashi }}{ }^{1} \mathbb{D}$, Masahiro Goto ${ }^{1,2}$ and Noriho Kamiya ${ }^{1,2, *(D)}$ \\ 1 Department of Applied Chemistry, School of Engineering, Kyushu University, Fukuoka 819-0395, Japan; \\ higuchi.ayato.808@s.kyushu-u.ac.jp (A.H.); obayashi.hiroki.495@s.kyushu-u.ac.jp (H.O.); \\ m-goto@mail.cstm.kyushu-u.ac.jp (M.G.) \\ 2 Center for Future Chemistry, Kyushu University, Fukuoka 819-0395, Japan \\ * Correspondence: wakabayashi.rie.122@m.kyushu-u.ac.jp (R.W.); kamiya.noriho.367@m.kyushu-u.ac.jp (N.K.); \\ Tel.: +81-92-802-2809 (R.W.); +81-92-802-2807 (N.K.) \\ + These authors equally contributed to this work.
}

\section{check for} updates

Citation: Wakabayashi, R.; Higuchi, A.; Obayashi, H.; Goto, M.; Kamiya, N. pH-Responsive Self-Assembly of Designer Aromatic Peptide Amphiphiles and Enzymatic Post-Modification of Assembled Structures. Int. J. Mol. Sci. 2021, 22, 3459. https://doi.org/10.3390/ ijms22073459

Academic Editor: Ayae SugawaraNarutaki

Received: 28 February 2021

Accepted: 25 March 2021

Published: 27 March 2021

Publisher's Note: MDPI stays neutral with regard to jurisdictional claims in published maps and institutional affiliations.

Copyright: (C) 2021 by the authors Licensee MDPI, Basel, Switzerland. This article is an open access article distributed under the terms and conditions of the Creative Commons Attribution (CC BY) license (https:/ creativecommons.org/licenses/by/ $4.0 /)$.

\begin{abstract}
Supramolecular fibrous materials in biological systems play important structural and functional roles, and therefore, there is a growing interest in synthetic materials that mimic such fibrils, especially those bearing enzymatic reactivity. In this study, we investigated the self-assembly and enzymatic post-modification of short aromatic peptide amphiphiles (PAs), Fmoc- $\mathrm{L}_{n} \mathrm{QG}$ ( $n=2$ or 3), which contain an LQG recognition unit for microbial transglutaminase (MTG). These aromatic PAs self-assemble into fibrous structures via $\pi-\pi$ stacking interactions between the Fmoc groups and hydrogen bonds between the peptides. The intermolecular interactions and morphologies of the assemblies were influenced by the solution $\mathrm{pH}$ because of the change in the ionization states of the C-terminal carboxy group of the peptides. Moreover, MTG-catalyzed post-modification of a small fluorescent molecule bearing an amine group also showed $\mathrm{pH}$ dependency, where the enzymatic reaction rate was increased at higher $\mathrm{pH}$, which may be because of the higher nucleophilicity of the amine group and the electrostatic interaction between MTG and the self-assembled Fmoc- $\mathrm{L}_{n} \mathrm{QG}$. Finally, the accumulation of the fluorescent molecule on these assembled materials was directly observed by confocal fluorescence images. Our study provides a method to accumulate functional molecules on supramolecular structures enzymatically with the morphology control.
\end{abstract}

Keywords: self-assembly; peptide amphiphile; enzymatic reaction; $\mathrm{pH}$-responsiveness; post-modification

\section{Introduction}

Supramolecular fibrils formed through molecular self-assembly are abundant in biological systems; examples include extracellular collagen matrices, intracellular actin filaments, and microtubules. They play important structural and functional roles. Synthetic approaches to fabricate materials that mimic such fibrils have been developed using various molecules [1,2]. Peptide amphiphiles (PAs) are one promising class of synthetic molecules used to fabricate such fibril-mimicking materials because of their design diversity and bio-functionality [3-8]. Artificial extracellular matrices, as well as drug delivery carriers with varied morphologies, mechanical properties, and biological epitopes have been reported thus far.

One important feature of these supramolecular materials is their responsiveness to external stimuli $[9,10]$. Since supramolecular organizations are dependent on relatively weak noncovalent interactions, they can be susceptible to external stimuli, such as light, temperature, and $\mathrm{pH}$. PAs often contain $\mathrm{pH}$-responsive side chains or an $\mathrm{N}$ - or C-terminus; therefore, $\mathrm{pH}$ is one of the most common stimuli used to control the assembly [11,12]. Indeed, many studies have shown $\mathrm{pH}$-induced changes in morphology [13] and mechanical 
properties [14], which resulted in functional materials, such as drug-releasing capsules [15, 16] and injectable cell delivery vehicles [14].

The use of enzymatic reactions to control morphologies or assembly formation is a relatively new concept in supramolecular materials $[17,18]$. Here, the chemical conversion of molecular structures is induced by an enzyme. There is a growing interest in such systems not only because of their analogy to biological systems, but also their controllability under biocompatible conditions. Various enzymes, including proteases [19,20], phosphatases [21], kinases [22], and tyrosinases [23] have been used to demonstrate this concept. In contrast, post-modification of supramolecular fibrils by enzymatic reactions is limited to a few reports [24-26]. This strategy contributes to adding functions or controlling hierarchical structures, or both, in biological systems [27,28]; however, there are limited number of enzymes capable of performing this task. Cross-linking enzymes, such as transglutaminase [29] and sortase [30], are some of the few limited enzymes.

We have previously reported on novel short aromatic peptide amphiphiles, 9fluorenylmethoxycarbonyl-(Leu) ${ }_{n}-\mathrm{Gln}-\mathrm{Gly}$ (Fmoc- $\mathrm{L}_{n} \mathrm{QG}, n=2$ or 3) [25]. These PAs contain a microbial transglutaminase (MTG)-reactive Gln residue. MTG catalyzes cross-linking reactions between the $\gamma$-carboxyamide of Gln and primary amines; thus Fmoc- $L_{n} Q G$ enables post-modification of the self-assembly structures with amine-containing molecules by the MTG reaction. A significant achievement from this work was that the post-modification was performed on different self-assembled structures, and the structure was depending on the number of Leu residues: specifically, narrow fibrils were formed by Fmoc- $\mathrm{L}_{2} \mathrm{QG}$, and wide, flat tapes from Fmoc- $\mathrm{L}_{3} \mathrm{QG}$.

In this study, we focused on the $\mathrm{pH}$ responsiveness of these assemblies. Since the free acid of the C-terminus shows different ionization states depending on the $\mathrm{pH}$, the self-assembly of Fmoc- $\mathrm{L}_{n} \mathrm{QG}$ should be influenced by the $\mathrm{pH}$. We first investigated the self-assembly of Fmoc- $\mathrm{L}_{n} \mathrm{QG}$ at four different $\mathrm{pH}$ values from $\mathrm{pH} 5$ to 8 . We then evaluated the enzymatic reaction on the Fmoc- $\mathrm{L}_{n} \mathrm{QG}$ assemblies at various $\mathrm{pH}$ values. Our results showed that both the self-assembly and enzymatic reaction are highly dependent on the $\mathrm{pH}$, while both were maintained (Figure 1).

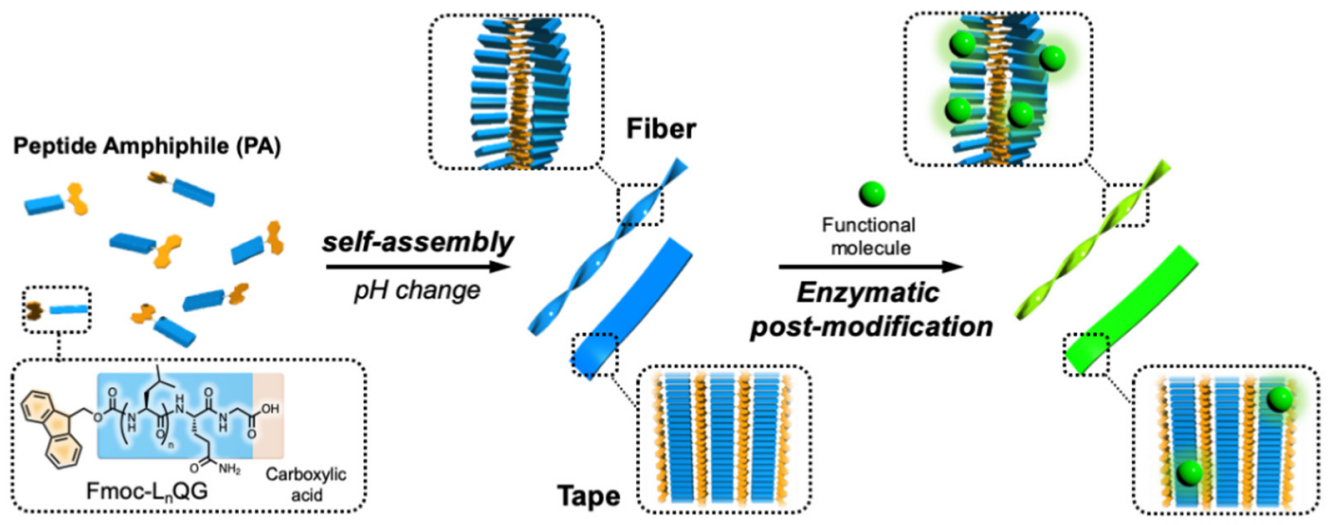

Figure 1. Conceptual diagram of this study. Short aromatic peptide amphiphiles bearing enzymatic reaction sites first self-assemble into different structures, then post-modification of the structures was achieved by the enzymatic reaction.

\section{Results and Discussion}

2.1. Change in Self-Organization Behavior of Fmoc- $L_{n} Q G(n=2,3)$ Depending on $p H$

2.1.1. Evaluation of Interaction between Fmoc Groups by Fluorescence Spectroscopy

Since the aromatic stacking interactions of short aromatic peptides have a large impact on the self-organization, we first evaluated the interaction between the Fmoc groups of Fmoc- $\mathrm{L}_{n} \mathrm{QG}(n=2,3)$ at $\mathrm{pH} 5-8$ by fluorescence spectroscopy below and above the critical aggregation concentrations (CAC values were $0.14,0.20,0.092$, and $0.53 \mathrm{mM}$ for Fmoc- $\mathrm{L}_{2} \mathrm{QG}$ and 0.089, 0.041, 0.14, and $0.091 \mathrm{mM}$ for Fmoc- $\mathrm{L}_{3} \mathrm{QG}$ at pH 5, 6, 7, and 8, 
respectively: Figure S2). For Fmoc- $\mathrm{L}_{2} \mathrm{QG}$ in a monomeric state $(0.005 \mathrm{mM})$, the maximum monomeric fluorescence was observed at $316 \mathrm{~nm}$ (Figure S3a). The peaks were shifted to $318 \mathrm{~nm}$ in an assembled state $(2.0 \mathrm{mM}$; Figure 2a) under all $\mathrm{pH}$ conditions ( $\mathrm{pH} 5-8)$, indicating the presence of excimers of fluorenes [31]. In addition, a broad peak at a longer wavelength around $450 \mathrm{~nm}$ was observed (Figure 2a), which corresponded to multiple aromatic stacking interactions ( $\pi-\pi$ interactions) between the Fmoc groups. While the fluorescence intensity around $450 \mathrm{~nm}$ decreased as the $\mathrm{pH}$ increased, with a significant decrease at $\mathrm{pH} 8$, the intensity of the excimer fluorescence $(\sim 318 \mathrm{~nm})$ increased at higher $\mathrm{pH}$, indicating the change in the $\pi-\pi$ interaction mode from long-range to short-range interaction. In Fmoc- $\mathrm{L}_{3} \mathrm{QG}$, the maximum wavelength of the monomeric fluorescence (314 $\mathrm{nm}$ at $0.005 \mathrm{mM}$ ) (Figure S3b) was shifted to $324 \mathrm{~nm}$ at all $\mathrm{pHs}$ when the concentration was above the CAC (Figure 2b). The intensity of the excimer fluorescence increased at higher $\mathrm{pH}$ as well. However, there was almost no broad peak around $450 \mathrm{~nm}$. These results suggest that the long-range $\pi-\pi$ interaction between Fmoc groups contributes to the higher-order aggregation of Fmoc- $\mathrm{L}_{2} \mathrm{QG}$, especially at lower $\mathrm{pH}$, while only a short-range interaction between Fmoc groups (excimer formation) was observed for the self-assembled Fmoc-L ${ }_{3} \mathrm{QG}$.

(a)

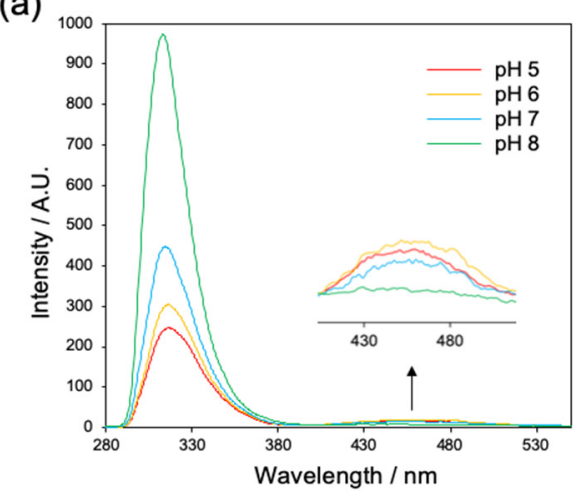

(b)

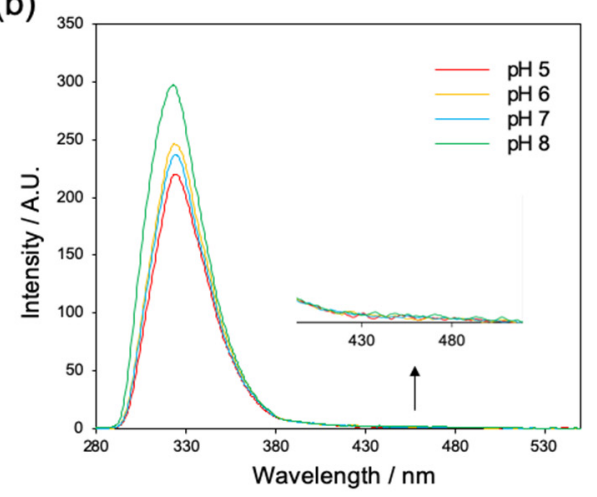

Figure 2. Fluorescence spectra of Fmoc- $\mathrm{L}_{2} \mathrm{QG}$ (a) and Fmoc- $\mathrm{L}_{3} \mathrm{QG}$ (b) at $\mathrm{pH}$ 5-8 above their critical aggregation concentrations (CACs). $\lambda_{\mathrm{ex}}=265 \mathrm{~nm}$.

2.1.2. Evaluation of Interaction between Peptides by Fourier Transform-Infrared Spectroscopy (FT-IR)

The formation of hydrogen bonds between peptides is another important factor in the self-assembly of short aromatic peptides. We used FT-IR to evaluate the effect of $\mathrm{pH}$ on the hydrogen bonding between peptides (Figure 3). The amide I band derived from the $\mathrm{C}=\mathrm{O}$ stretching vibration of the amide groups is an indicator of the strength of hydrogen bonds between peptides. Both Fmoc- $\mathrm{L}_{2} \mathrm{QG}$ and Fmoc- $\mathrm{L}_{3} \mathrm{QG}$ assemblies showed an amide I band around $1635 \mathrm{~cm}^{-1}$, indicating the formation of a $\beta$-sheet structure (Figure $3 a, b$ ). Fmoc$\mathrm{L}_{3} \mathrm{QG}$ assemblies showed absorption at lower wavenumbers than Fmoc- $\mathrm{L}_{2} \mathrm{QG}$ assemblies. Moreover, the band shifted to a lower wavenumber as the $\mathrm{pH}$ increased (Figure 3c). These results indicate that the hydrogen bonds formed between the peptides are stronger in Fmoc- $\mathrm{L}_{3} \mathrm{QG}$ assemblies, especially at higher $\mathrm{pH}$. An additional peak around $1690 \mathrm{~cm}^{-1}$ corresponds to the organized carbamate structure of the Fmoc groups.

2.1.3. Evaluation of the Self-Assembled Structure of Fmoc- $\mathrm{L}_{n} \mathrm{QG}$ in Response to $\mathrm{pH}$ by Transmission Electron Microscopy (TEM)

We observed how the self-assembled structures of Fmoc- $\mathrm{L}_{n} \mathrm{QG}(n=2,3)$ changed with $\mathrm{pH}$ using transmission electron microscopy (TEM) (Figure 4). Fmoc- $\mathrm{L}_{2} \mathrm{QG}$ assemblies formed narrow fiber-like structures with a twisted morphology at all $\mathrm{pH}$ regions between 5 and 8 (Figure $4 \mathrm{a}-\mathrm{d}$ ). The diameter of the fibers remained almost identical (ca. $10 \mathrm{~nm}$ ), while the twisting was most pronounced at $\mathrm{pH} 5$ (Figure 4a). Similarly, Fmoc-L $\mathrm{L}_{3} \mathrm{QG}$ formed fibrous assemblies with a twisted structure at $\mathrm{pH} 5$ and 6 (Figure 4e,f). However, as the $\mathrm{pH}$ 
increases, a wide, flat, tape-like morphology appeared (Figure 4g,h). At pH 8, almost all assemblies were transformed into tape-like structures with a width of ca. $200 \mathrm{~nm}$, which was ca. 12.5-fold wider than those at pH 5 (Figure 4h).

(a)

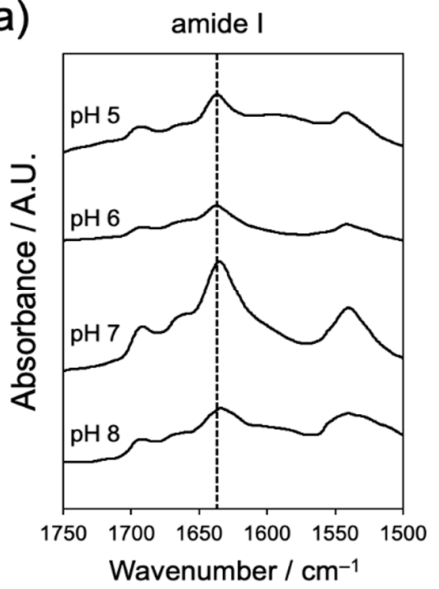

(b)

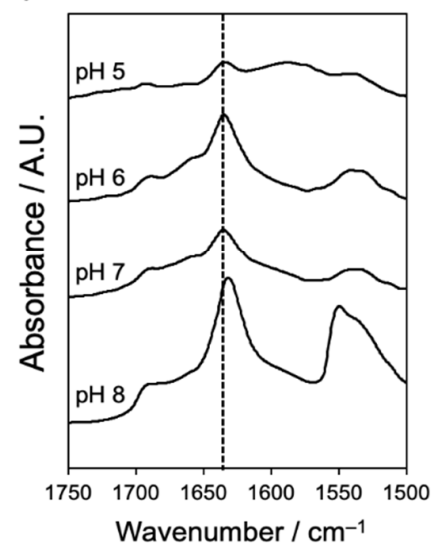

(c)

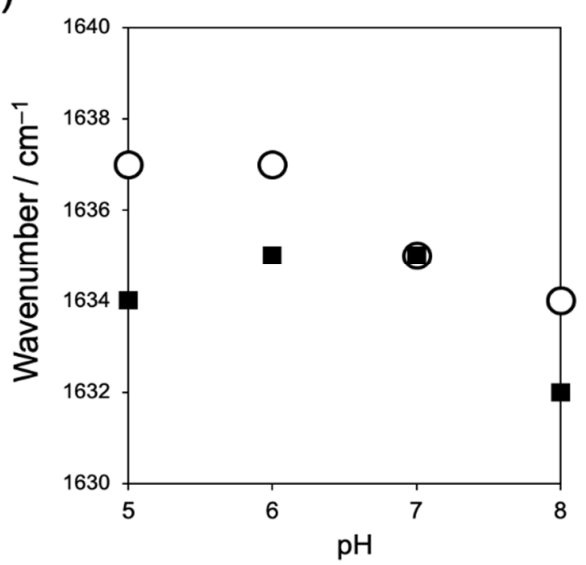

Figure 3. (a,b) Fourier transform-infrared spectroscopy (FT-IR) spectra of Fmoc- $\mathrm{L}_{2} \mathrm{QG}(\mathbf{a})$ and Fmoc- $\mathrm{L}_{3} \mathrm{QG}(\mathbf{b})$ at $\mathrm{pH}$ 5-8 and (c) amide I peak positions of Fmoc- $\mathrm{L}_{2} \mathrm{QG}$ (open circle) and Fmoc- $\mathrm{L}_{3} \mathrm{QG}$ (closed square) at pH 5-8.

(a)

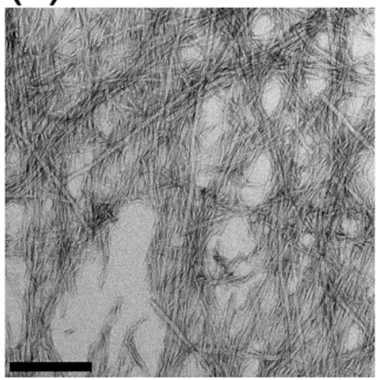

(e)

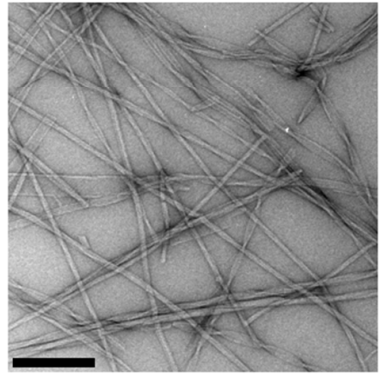

(b)

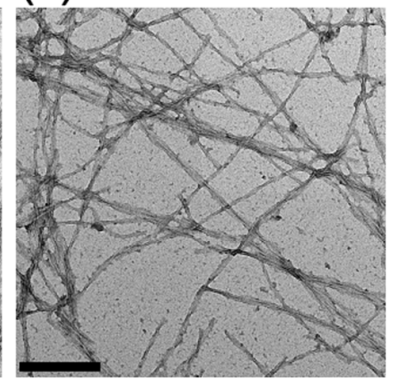

(f)

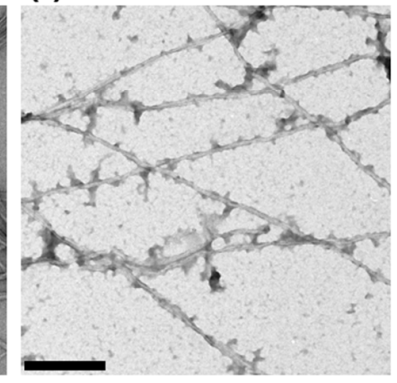

(c)

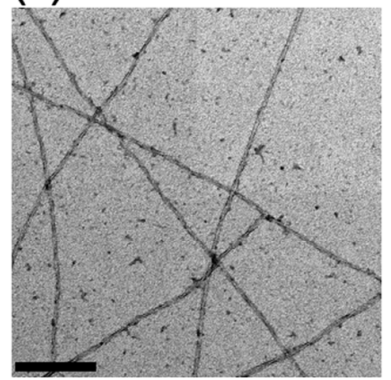

(g)

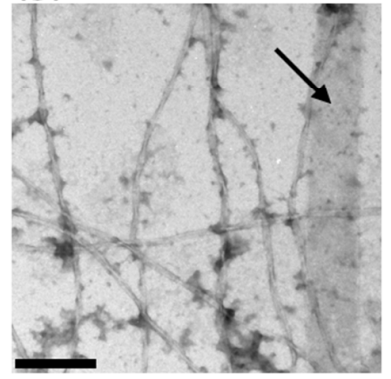

(d)

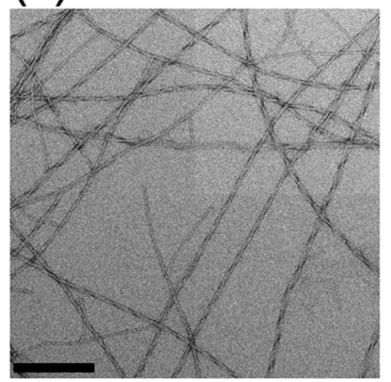

(h)

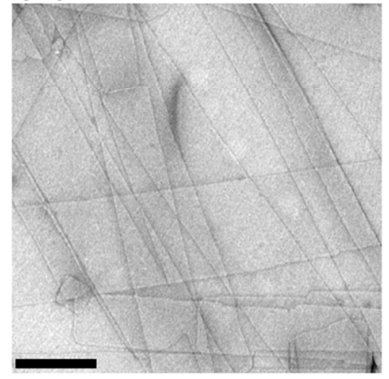

Figure 4. Transmission electron microscopy (TEM) images of Fmoc- $\mathrm{L}_{2} \mathrm{QG}(\mathbf{a}-\mathbf{d})$ and Fmoc- $\mathrm{L}_{3} \mathrm{QG}(\mathbf{e}-\mathbf{h})$ at $\mathrm{pH} 5(\mathbf{a}, \mathbf{e}), 6(\mathbf{b}, \mathbf{f})$, $7(\mathbf{c}, \mathbf{g})$, and 8 (d,h). Fmoc- $\mathrm{L}_{2} \mathrm{QG}$ assemblies formed a narrow fibrous structure with twisting (a-d). Fmoc- $\mathrm{L}_{3} \mathrm{QG}$ assemblies formed a similar structure at $\mathrm{pH}$ 5-6 (e,f), while they transformed into a wide, flat tape-like structure as the $\mathrm{pH}$ increased $(\mathbf{g}, \mathbf{h})$. Arrow in (g) indicates the flat tape-like structure. Bars: $200 \mathrm{~nm}$.

In Fmoc- $\mathrm{L}_{2} \mathrm{QG}$ assemblies, long-range $\pi-\pi$ interactions between the Fmoc groups operate, while (relatively) weak hydrogen bonds between the peptides are also in play. In contrast, in Fmoc- $\mathrm{L}_{3} \mathrm{QG}$ assemblies, the $\pi-\pi$ stacking interactions are only effective at a short range, and strong hydrogen bond formation is the main driving force of the self-assembly. Although the self-assembled morphologies of Fmoc- $\mathrm{L}_{2} \mathrm{QG}$ at pH 5-8 and Fmoc- $\mathrm{L}_{3} \mathrm{QG}$ at low $\mathrm{pH}(\mathrm{pH} 5$ and 6) look similar, the molecular organization may differ. Moreover, Fmoc- $\mathrm{L}_{3} \mathrm{QG}$ at $\mathrm{pH} 8$ showed a drastic morphological change to tape-like structures. This may stem from the additional interaction between the hydrophobic peptide sequence, $\mathrm{L}_{3}$, 
as a result of the stronger hydrogen bond formation, leading to the formation of hierarchical assemblies between fibers.

\subsection{Enzymatic Modification of Fmoc- $L_{n} Q G(n=2,3)$ Assemblies with Small} Fluorescent Substrates

2.2.1. Conjugation of Fmoc- $\mathrm{L}_{n} \mathrm{QG}$ and Oregon Green 488 Cadaverine (OG) by MTG Catalysis

Next, we evaluated the enzymatic reaction rate of MTG using Fmoc- $L_{n} Q G$ and a small fluorescent substrate with a primary amine, Oregon green 488 cadaverine (OG) at different $\mathrm{pHs}$. Assemblies of Fmoc- $\mathrm{L}_{n} \mathrm{QG}$ were formed, and the MTG reaction with OG was performed at $25{ }^{\circ} \mathrm{C}$ for $2 \mathrm{~h}$. The conjugation of OG with Fmoc- $\mathrm{L}_{n} \mathrm{QG}$ was confirmed by Matrix Assisted Laser Desorption/Ionization Time Of Flight Mass Spectrometry (MALDI TOF MS) (Figure S4). Analysis by HPLC indicated that the enzymatic reaction rate increased as the $\mathrm{pH}$ increased for both Fmoc- $\mathrm{L}_{n} \mathrm{QG}$ assemblies (Figure 5). Given that the enzymatic activity of MTG measured by the hydroxamate method [32] was almost identical under all $\mathrm{pH}$ conditions between $\mathrm{pH} 5$ and 8 (Figure S5a,b), the difference in the reaction rates is a result of the substrates, Fmoc- $\mathrm{L}_{\mathrm{n}} \mathrm{QG}$ or OG.

(a)

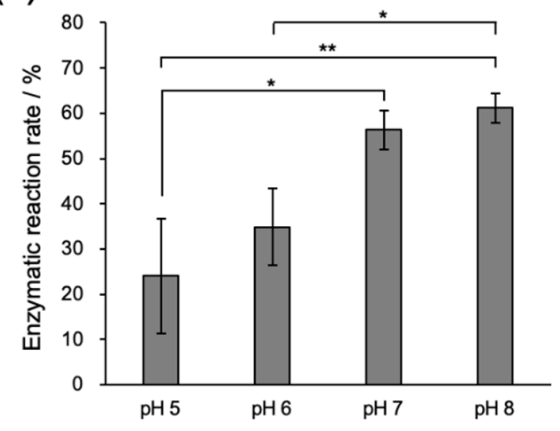

(b)

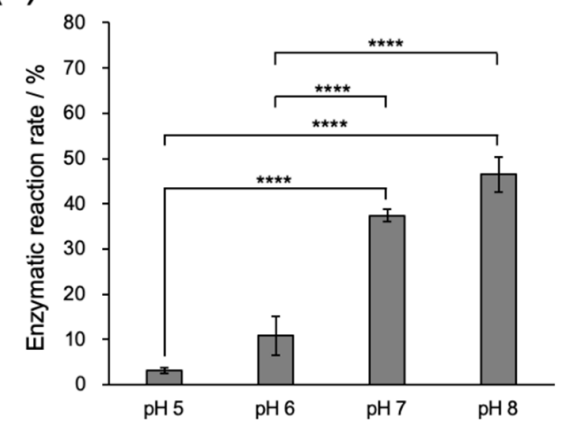

Figure 5. Microbial transglutaminase (MTG) enzymatic reaction rates of (a) Fmoc- $\mathrm{L}_{2} \mathrm{QG}$ and (b) Fmoc- $\mathrm{L}_{3} \mathrm{QG}$ in an assembled state. The enzymatic reaction was performed with Oregon green 488 cadaverine (OG) as an amine substrate. $n=3, * p<0.05$, ** $p<0.01,{ }^{* * * *} p<0.0001$.

To investigate the influence of the electric charge of the amine substrates, OG was changed to tetramethylrhodamine cadaverine and sulforhodamine cadaverine, which have cationic properties on their aromatic rings. Similarly to OG, the enzyme reaction rates increased at higher $\mathrm{pH}$ (Figure S6a-d), suggesting that the net charge of the amine substrate does not directly affect the enzymatic reaction. However, a possibility remains that the $\mathrm{pH}$ dependency in the enzymatic rates was because of the amine substrate and its nucleophilicity, which has an intrinsic $\mathrm{pH}$ dependency. In fact, initial velocities of the MTG reaction using a simple amine substrate, acetyl-L-lysine, were highly dependent on $\mathrm{pH}$ when Fmoc- $\mathrm{L}_{n} \mathrm{QG}$ in an unassembled state or Z-QG was used as the glutamine substrate (Figures S7 and S8).

In the case of the assembled glutamine substrate, Fmoc- $L_{n} Q G$ assemblies, we evaluated the apparent $\mathrm{pKa}$ values by a titration method. Although the theoretical $\mathrm{pKa}$ value of the carboxy group of a C-terminal amino acid of Fmoc- $\mathrm{L}_{n} \mathrm{QG}$, glycine is ca. 3.5, the value can shift because of the influence of neighboring molecules in an assembled state [31]. The apparent pKa values indeed shifted to 6.2-8.1 and 5.8-7.9 for Fmoc- $\mathrm{L}_{2} \mathrm{QG}$ and Fmoc- $\mathrm{L}_{3} \mathrm{QG}$, respectively, with the inflection point around 7 (Figure S9). Considering that the pI of MTG is 8.9, the accessibility of MTG to Fmoc- $\mathrm{L}_{n} \mathrm{QG}$ assemblies may increase above $\mathrm{pH}$ 7. In addition, enhanced hydrogen bonding between the peptides at higher $\mathrm{pH}$ (Figure 3 ) increases the apparent concentration of the Gln substrate at the enzymatic reaction site, which may increase the affinity to MTG. Taken together, higher $\mathrm{pH}$ optimized the environment for the enzymatic reaction for both the amine and assembled glutamine substrates, which results in the higher reaction rates found in Figure 5. 


\subsubsection{Confocal Fluorescence Microscope Images of OG on Fmoc- $\mathrm{L}_{n} \mathrm{QG}$ Peptide Assemblies}

Finally, we confirmed the accumulation of OG on the Fmoc- $L_{n} Q G$ assemblies by observation with confocal laser scanning microscopy (CLSM) [33]. In both PA assemblies, green fluorescence from OG was observed at the overlap region of thioflavin $\mathrm{T}$ (ThT)stained PA assemblies after the MTG reaction (Figure 6a,b; right panels). In contrast, in the control samples without an MTG reaction, no fluorescence from OG was observed on the PA assemblies (Figure 6a,b; left panels). Despite the low reaction rates at low $\mathrm{pH}$, especially for Fmoc- $\mathrm{L}_{3} \mathrm{QG}$ (Figure 5), a sharp contrast in the fluorescence of OG between with (right panels) and without (left panels) MTG reaction samples was observed. The contrast was more obvious with samples that showed high reaction rates, such as Fmoc- $\mathrm{L}_{2} \mathrm{QG}$ at $\mathrm{pH} 7$ and 8 , where the green fluorescence derived from OG was uniformly found throughout the peptide assembly structures (Figure 6a, right panels). These results suggest that the specific accumulation of OG on the Fmoc- $\mathrm{L}_{n} \mathrm{QG}$ assemblies was achieved by the MTG reaction under all the $\mathrm{pH}$ conditions examined, though the accumulation ratio depended on the reaction rates, and the accumulation was directly observed using a CLSM technique.

(a)
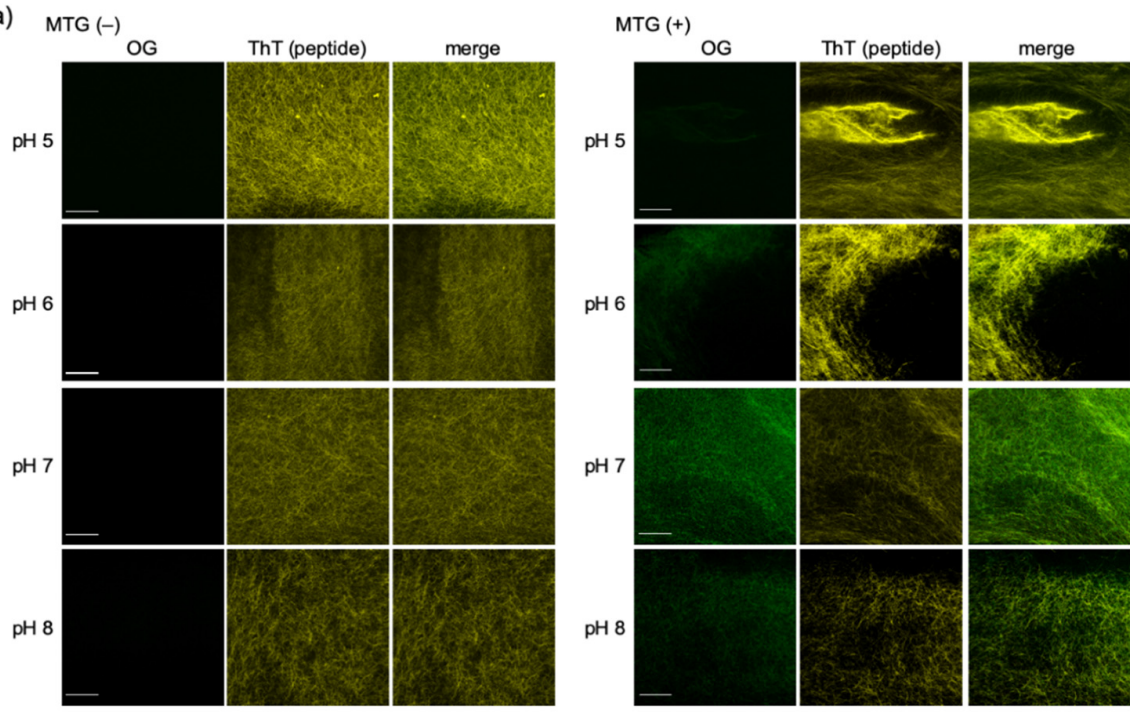

(b) MTG (-)
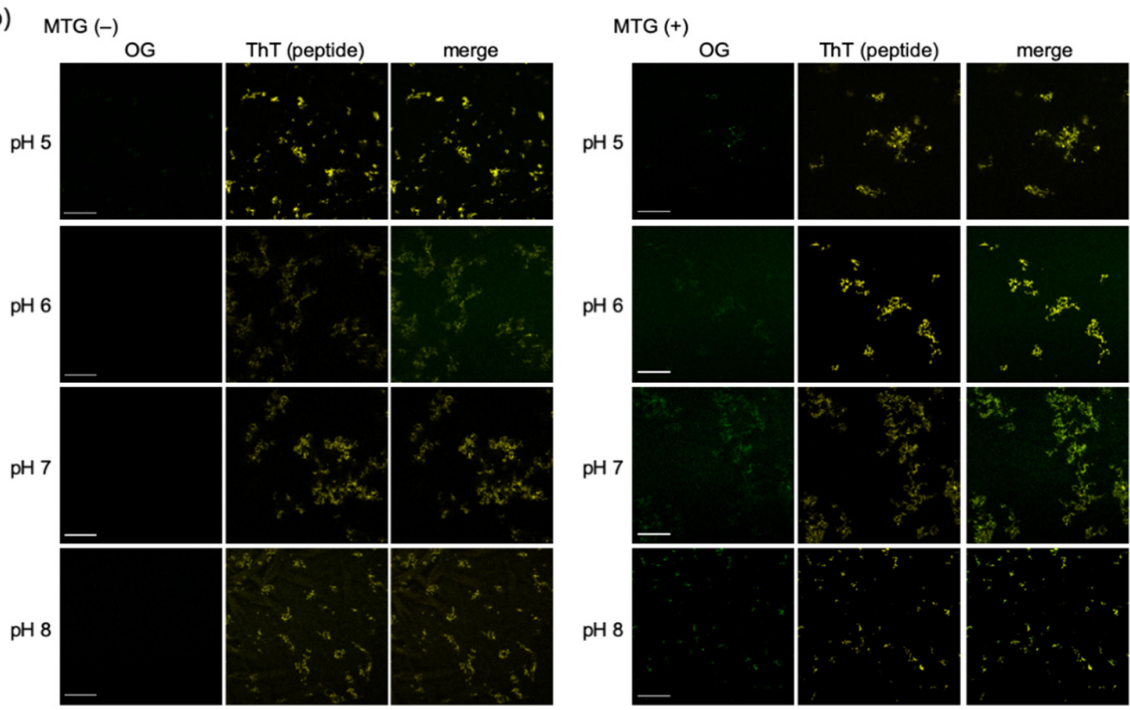

Figure 6. Confocal laser scanning microscopy (CLSM) images of Fmoc- $\mathrm{L}_{2} \mathrm{QG}$ (a) and Fmoc- $\mathrm{L}_{3} \mathrm{QG}$ (b) assemblies at $\mathrm{pH}$ 5-8 with and without the MTG reaction. Green fluorescence derived from Oregon green 488 cadaverine (OG) was observed at the overlap region with the fluorescence of thioflavin T (ThT)-stained peptide amphiphile (PA) assemblies for samples with the MTG reaction. Bars: $20 \mu \mathrm{m}$. 


\section{Experimental Section}

3.1. General

Amino acid reagents and resin for the synthesis of PA, Fmoc-Gly-Alko-resin, Fmoc-Leu-OH, Fmoc-Gln(Trt)-OH, O-(1H-benzotriazol-1-yl)- $\mathrm{N}, \mathrm{N}_{,} \mathrm{N}^{\prime}, \mathrm{N}^{\prime}$-tetramethyluronium hexafluorophosphate (HBTU), 1-hydroxy-1-H-benzotriazole hydrate (HOBt), N,N-diisopropylethylamine (DIEA), piperidine, trifluoroacetic acid (TFA), N $\alpha$-acetyl-L-lysine(acetyl-L-Lys), and triisopropylsilane (TIS) were purchased from Watanabe Chemical Industries (Hiroshima, Japan). Reagents for the Kaiser test were purchased from Kokusan Chemical (Tokyo, Japan). Methanol, dichloromethane, diethyl ether, acetonitrile (ACN), Nile red, sodium hydrogenphosphate dodecahydrate, and trizma base were obtained from Wako Pure Chemical Industries (Osaka, Japan). N,N-dimethylformamide (DMF), N-ethylmaleimide (NEM), dimethyl sulfoxide (DMSO), triethylamine (TEA), acetic acid (AcOH), citric acid, sodium dihydrogenphosphate dihydrate, and hydrochloric acid were purchased from Kishida Chemical (Osaka, Japan). Oregon green 488 cadaverine, fluorescein cadaverine, and sulforhodamine cadaverine were purchased from Thermo Fisher Scientific (Waltham, MA, USA). Tetramethylrhodamine cadaverine was purchased from Cosmo Bio (Tokyo, Japan). Thioflavin T (ThT) was obtained from Sigma Aldrich (St. Louis, MO, USA). Trifluoroethanol (TFE) was obtained from Tokyo Chemical industry (Tokyo, Japan). Tri-sodium citrate dihydrate was purchased from Nacalai Tesque (Kyoto, Japan). All chemicals and solvents were used as received. In this study, the following buffer solutions were used: sodium citrate buffer for $\mathrm{pH} 5$, phosphate buffer for $\mathrm{pH} 6$ and 7, and Tris- $\mathrm{HCl}$ buffer for $\mathrm{pH} 8$. The concentrations of buffer were set to $10 \mathrm{mM}$ except for that shown in Figure S5b.

\subsection{Synthesis of Aromatic Peptide Amphiphiles}

Fmoc- $\mathrm{L}_{\mathrm{n}} \mathrm{QG}(n=2,3)$ were synthesized by the standard 9-fluorenylmethoxycarbonyl (Fmoc) solid-phase peptide synthesis method. Fmoc-Gly-Alko Resin was immersed in dichloromethane for $30 \mathrm{~min}$. The protective Fmoc group was removed using $20 \%$ piperidine in DMF. The deprotection was confirmed by Kaiser tests. Coupling reactions of each amino acid were conducted by adding a mixture of coupling reagents (Fmoc-amino acid:HBTU:HOBt:DIEA = 3:3:3:6 mol equivalent to reactive sites on resin) in DMF to the resin and shaken for $1 \mathrm{~h}$. After coupling reactions, the protective Fmoc group was removed by $20 \%$ piperidine in DMF except for the last amino acid. The aromatic peptides were cleaved from the resin using a mixture of $95 \%$ TFA, $2.5 \%$ TIS, and $2.5 \%$ water for $1.5 \mathrm{~h}$. After removing the solvents under reduced pressure, the peptides were precipitated and washed with cold diethyl ether.

The crude peptide solids were collected, dissolved in the mixture of DMSO, TFE, and a $0.1 \%$ aqueous solution of TEA/ $\mathrm{AcOH}(11: 2(v / v))$ with 2:2:6 $(v / v / v)$ ratio, and purified by reverse-phase high pressure liquid chromatography (HPLC) on Inertsil ODS-3 column (GL Science, Tokyo, Japan) using a gradient of water and acetonitrile both containing $0.1 \% \mathrm{TEA} / \mathrm{AcOH}$. The fractions with each PA were collected, lyophilized, and stored at $-20{ }^{\circ} \mathrm{C}$ until use. The purified peptides were analyzed by HPLC (Inertsil ODS-3 column, GL science, Tokyo, Japan) and MALDI TOF MS (Autoflex-III, Bruker, Billerica, MA, USA) using $\alpha$-cyano-4-hydroxycinnamic acid (CHCA, Sigma-Aldrich (St. Louis, MO, USA)) as the matrix.

\subsection{Preparation of $M T G$}

MTG was recombinantly prepared in Escherichia coli BL21 star (DE3) as previously reported [34]. Briefly, a chimera protein of maltose-binding protein and tobacco etch virus protease (MBP-TEV) was fused to the N-terminus of Streptomyces mobaraensis MTG. The TEV protease recognition sequence (ENLFYQS) was inserted between the propeptide domain and the catalytic domain of MTG. Two mutations, K10R and Y12A, were introduced to the propeptide domain. The active MTG without the propeptide domain was prepared by a self-cleavage reaction of the MBPTEV-propeptide-MTG. The expressed active MTG was purified with a NiNTA column (HisTrap FF Crude, $5 \mathrm{~mL}$, Cytiva, Tokyo, Japan), and a 
size-exclusion column (HiLoad 16/600 Superdex 75 pg, Cytiva) using standard protocols. The amino acid sequence of the active MTG prepared is shown below.

SGGGGSDSDDRVTPPAEPLDRMPDPYRPSYGRAETVVNNYIRWQQVYSHRDGRKQQ MTEEQREWLSYGCVGVTWVNSGQYPTNRLAFASFDEDRFKNELKNGRPRSGETRAE FEGRVAKESFDEEKGFQRAREVASVMNRALENAHDESAYLDNLKKELANGNDALR NEDARSPFYSALRNTPSFKERNGGNHDPSRMKAVIYSKHFWSGQDRSSSADKRKYGD PDAFRPAPGTGLVDMSRDRNIPRSPTSPGEGFVNFDYGWFGAQTEADADKTVWTHG NHYHAPNGSLGAMHVYESKFRNWSEGYSDFDRGAYVITFIPKSWNTAPDKVKQGW $\mathrm{P}$

\subsection{Critical Aggregation Concentration (CAC)}

Various concentrations of Fmoc- $\mathrm{L}_{n} \mathrm{QG}(n=2,3)$ samples were prepared in $10 \mathrm{mM}$ buffer at pH 5-8. For each peptide solution, the fluorescent dye, Nile red, was added at a final concentration of $1 \mu \mathrm{M}$ and incubated overnight at room temperature. The fluorescence intensity at $635 \mathrm{~nm}$ (excitation wavelength $560 \mathrm{~nm}$ ) of each sample was measured using a microplate reader (SpectraMax i3x, Molecular Device, San Jose, CA, USA) and plotted against the peptide concentration to create a CAC plot.

\subsection{Fluorescence Spectra}

Fmoc- $\mathrm{L}_{2} \mathrm{QG}(0.005$ or $2.0 \mathrm{mM})$ and $F m o c-\mathrm{L}_{3} \mathrm{QG}(0.005$ or $1.0 \mathrm{mM})$ were prepared as the self-assembled (2.0 and $1.0 \mathrm{mM}$ for Fmoc- $\mathrm{L}_{2} \mathrm{QG}$ and Fmoc- $\mathrm{L}_{3} \mathrm{QG}$, respectively) or un-assembled $(0.005 \mathrm{mM})$ samples. Fluorescence spectra were acquired from 270 to $550 \mathrm{~nm}$ by exciting at $265 \mathrm{~nm}$. Fluorescence spectra were measured using an LS55 fluorescence spectrometer (PerkinElmer, Waltham, MA, USA).

\subsection{Fourier-Transform Infrared Spectroscopy (FT-IR)}

Fmoc- $\mathrm{L}_{2} \mathrm{QG}(2.0 \mathrm{mM})$ and Fmoc- $\mathrm{L}_{3} \mathrm{QG}(1.0 \mathrm{mM})$ were prepared in $10 \mathrm{mM}$ buffer at $\mathrm{pH}$ 5-8 and lyophilized. Fourier-transform infrared (FT-IR) spectra were recorded on Spectrum Two (PerkinElmer) in ATR mode. A resolution of $2 \mathrm{~cm}^{-1}$ was used.

\subsection{Transmission Electron Microscopy (TEM)}

Fmoc- $\mathrm{L}_{2} \mathrm{QG}(2.0 \mathrm{mM})$ and Fmoc- $\mathrm{L}_{3} \mathrm{QG}(1.0 \mathrm{mM})$ were prepared in $10 \mathrm{mM}$ buffer at $\mathrm{pH}$ 5-8. Three microliters of each sample were drop-cast onto a hydrophilized STEM grid with an elastic carbon film (Okenshoji, Tokyo, Japan). After $1.5 \mathrm{~min}$ of incubation, the excess solution was removed and then stained with $2 \%$ uranyl solution for $2 \mathrm{~min}$. The transmission electron microscopy (TEM) images were taken by JEM-2010 (JEOL, Tokyo, Japan) with an accelerating voltage of $120 \mathrm{kV}$.

\subsection{Conjugation of Fmoc- $L_{n} Q G$ and Oregon Green Cadaverine (OG) by MTG Catalysis}

A reaction sample of each self-assembled PA was prepared in $10 \mathrm{mM}$ buffer at each $\mathrm{pH}$ $\left(\left[\right.\right.$ Fmoc- $\left.\mathrm{L}_{2} \mathrm{QG}\right]=2.0 \mathrm{mM},\left[\right.$ Fmoc- $\left.\mathrm{L}_{3} \mathrm{QG}\right]=1.0 \mathrm{mM}$, Fmoc- $\left.\mathrm{L}_{\mathrm{n}} \mathrm{QG}: \mathrm{OG}=10: 1(\mathrm{~mol}: \mathrm{mol})\right)$. MTG $(0.3 \mathrm{U} / \mathrm{mL})$ was added to the samples, and the reaction was allowed to proceed at $25^{\circ} \mathrm{C}$ for $2 \mathrm{~h}$. After the reaction, NEM at a final concentration of $1 \mathrm{mM}$ was added to inactivate the MTG. The enzymatic reaction rate at each $\mathrm{pH}$ was evaluated by HPLC analysis on an Inertsil ODS-3 $(4.6 \times 250 \mathrm{~nm})$ column. The gradient was from $40 \%$ to $80 \%$ with $0.1 \%$ TFA $\mathrm{ACN}$ solution, and the flow rate was $1 \mathrm{~mL} / \mathrm{min}$. The OG-containing-eluents were detected at $488 \mathrm{~nm}$.

\subsection{Confocal Fluorescence Microscope Images of OG on Fmoc- $L_{n} Q G$ Peptide Assemblies}

An aqueous solution of ThT at a final concentration of $10 \mu \mathrm{M}$ was added to the reaction samples. The droplets of samples $(2.5 \mu \mathrm{L})$ were transferred into multi-well glass-bottom dishes (Matsunami Glass Ind., Osaka, Japan), and $2.5 \mu \mathrm{L}$ of $10 \mathrm{mM} \mathrm{CaCl}_{2}$ solution was added. The confocal images were taken using LSM700 (Carl Zeiss, Oberkochen, Germany) with diode lasers (405 $\mathrm{nm}$ for ThT, $488 \mathrm{~nm}$ for OG). 


\section{Conclusions}

In this study, we used two short aromatic peptide amphiphiles with MTG reactivity, Fmoc- $\mathrm{L}_{2} \mathrm{QG}$ and Fmoc- $\mathrm{L}_{3} \mathrm{QG}$, to examine the $\mathrm{pH}$ responsiveness of their self-assembly and enzymatic reactions. These PAs self-assemble via $\pi-\pi$ stacking interactions between the Fmoc groups and hydrogen bonds between peptides. The intermolecular interactions were influenced by $\mathrm{pH}$; a change in $\pi-\pi$ stacking mode from long-range to short-range interaction and an increase in hydrogen bonding were observed when the solution $\mathrm{pH}$ was increased from $\mathrm{pH} 5$ to 8 . A dramatic morphological change was observed for Fmoc- $\mathrm{L}_{3} \mathrm{QG}$ from twisted fibers at $\mathrm{pH} 5$ to wide, flat, tape-like structures at $\mathrm{pH}$ 8. In the post-modification of a small fluorescent substrate, Oregon green 488 cadaverine, on these Fmoc- $\mathrm{L}_{n} \mathrm{QG}$ assemblies, the rate of modification increased at higher $\mathrm{pH}$, presumably because of the higher nucleophilicity of the amine group and increased accessibility of MTG to the assembled Gln substrates. Finally, direct observation of the accumulation of OG on the Fmoc- $\mathrm{L}_{n} \mathrm{QG}$ assemblies was achieved using CLSM. Our study demonstrates the functionalization of supramolecular fibrous materials while also controlling their supramolecular structures. This will provide a new strategy to engineer functional biomimetic nanomaterials for various applications in the biomedical field.

Supplementary Materials: Supplementary Materials can be found at https://www.mdpi.com/ article/10.3390/ijms22073459/s1.

Author Contributions: Conceptualization, R.W. and N.K.; methodology, R.W.; validation, A.H. and H.O.; investigation, R.W. and A.H.; resources, R.W. and A.H.; data curation, R.W. and A.H.; writingoriginal draft preparation, R.W. and A.H.; writing-review and editing, H.O., M.G., and N.K.; visualization, R.W. and A.H.; supervision, R.W. and N.K.; project administration, R.W.; funding acquisition, R.W. and N.K. All authors have read and agreed to the published version of the manuscript.

Funding: This research was funded by the Japan Society for the Promotion of Science (JSPS) KAKENHI grant numbers No. JP18K04855 and JP19H00841.

Acknowledgments: R.W. thanks the Japan Association for Chemical Innovation, Iketani Science and Technology Foundation, Shiseido Female Researcher Science Grant for a research grant. The authors thank the Nanotechnology Platform Program of the Ministry of Education, Culture, Sports, Science, and Technology (MEXT) for the facility support. The authors also thank Kosuke Minamihata, Ryo Sato, Ryutaro Ariyoshi, Hiromasa Taniguchi (Kyushu University) for assistance in the preparation of MTG. A.H. thanks the Kyushu University Program for Leading Graduate Schools, Advanced Graduate da Vinci Course on Molecular Systems for Devices, and H.O. thanks the Kyushu University Program for Leading Graduate Schools, Advanced Graduate Course on Molecular Systems for Devices, for scholarship.

Conflicts of Interest: The authors declare no conflict of interest.
Abbreviations
MTG Microbial transglutaminase
CAC Critical aggregation concentration
FT-IR Fourier transform infrared spectroscopy
TEM Transmission electron microscopy
OG Oregon green 488 cadaverine
CLSM Confocal laser scanning microscopy

\section{References}

1. Webber, M.J.; Appel, E.A.; Meijer, E.W.; Langer, R. Supramolecular biomaterials. Nat. Mater. 2015, 15, 13-26. [CrossRef]

2. Aida, T.; Meijer, E.W.; Stupp, S.I. Functional supramolecular polymers. Science 2012, 335, 813-817. [CrossRef] [PubMed]

3. Li, J.; Xing, R.; Bai, S.; Yan, X. Recent advances of self-assembling peptide-based hydrogels for biomedical applications. Soft Matter 2019, 15, 1704-1715. [CrossRef] [PubMed]

4. Sato, K.; Hendricks, M.P.; Palmer, L.C.; Stupp, S.I. Peptide supramolecular materials for therapeutics. Chem. Soc. Rev. 2018, 47, 7539-7551. [CrossRef] 
5. Hauser, C.A.E.; Zhang, S. Designer self-assembling peptide nanofiber biological materials. Chem. Soc. Rev. 2010, 39, $2780-2790$. [CrossRef] [PubMed]

6. Hamley, I.W. Self-assembly of amphiphilic peptides. Soft Matter 2011, 7, 4122-4138. [CrossRef]

7. Cui, H.; Webber, M.J.; Stupp, S.I. Self-assembly of peptide amphiphiles: From molecules to nanostructures to biomaterials. Biopolymers 2010, 94, 1-18. [CrossRef] [PubMed]

8. Inaba, H.; Matsuura, K. Peptide Nanomaterials Designed from Natural Supramolecular Systems. Chem. Rec. 2019, 19, 843-858. [CrossRef] [PubMed]

9. Mart, R.J.; Osborne, R.D.; Stevens, M.M.; Ulijn, R.V. Peptide-based stimuli-responsive biomaterials. Soft Matter $2006,2,822$. [CrossRef]

10. Shigemitsu, H.; Hamachi, I. Design Strategies of Stimuli-Responsive Supramolecular Hydrogels Relying on Structural Analyses and Cell-Mimicking Approaches. Acc. Chem. Res. 2017, 50, 740-750. [CrossRef]

11. Ghosh, G.; Barman, R.; Sarkar, J.; Ghosh, S. pH-Responsive Biocompatible Supramolecular Peptide Hydrogel. J. Phys. Chem. B 2019, 123, 5909-5915. [CrossRef]

12. Sarkar, A.; Kölsch, J.C.; Berač, C.M.; Venugopal, A.; Sasmal, R.; Otter, R.; Besenius, P.; George, S.J. Impact of NDI-Core Substitution on the pH-Responsive Nature of Peptide-Tethered Luminescent Supramolecular Polymers. Chem. Open 2020, 9, 346-350. [CrossRef]

13. Gao, C.; Li, H.; Li, Y.; Kewalramani, S.; Palmer, L.C.; Dravid, V.P.; Stupp, S.I.; Olvera De La Cruz, M.; Bedzyk, M.J. Electrostatic Control of Polymorphism in Charged Amphiphile Assemblies. J. Phys. Chem. B 2017, 121, 1623-1628. [CrossRef] [PubMed]

14. Tang, J.D.; Mura, C.; Lampe, K.J. Stimuli-Responsive, Pentapeptide, Nanofiber Hydrogel for Tissue Engineering. J. Am. Chem. Soc. 2019, 141, 4886-4899. [CrossRef] [PubMed]

15. Li, X.; Fu, M.; Wu, J.; Zhang, C.; Deng, X.; Dhinakar, A.; Huang, W.; Qian, H.; Ge, L. pH-sensitive peptide hydrogel for glucose-responsive insulin delivery. Acta Biomater. 2017, 51, 294-303. [CrossRef]

16. Ahlers, P.; Frisch, H.; Holm, R.; Spitzer, D.; Barz, M.; Besenius, P. Tuning the pH-Switch of Supramolecular Polymer Carriers for siRNA to Physiologically Relevant pH. Macromol. Biosci. 2017, 17, 1-7. [CrossRef]

17. Williams, R.J.; Mart, R.J.; Ulijn, R.V. Exploiting biocatalysis in peptide self-assembly. Biopolymers 2010, 94, 107-117. [CrossRef]

18. He, H.; Tan, W.; Guo, J.; Yi, M.; Shy, A.N.; Xu, B. Enzymatic Noncovalent Synthesis. Chem. Rev. 2020, 120, 9994-10078. [CrossRef] [PubMed]

19. Hirst, A.R.; Roy, S.; Arora, M.; Das, A.K.; Hodson, N.; Murray, P.; Marshall, S.; Javid, N.; Sefcik, J.; Boekhoven, J.; et al. Biocatalytic induction of supramolecular order. Nat. Chem. 2010, 2, 1089-1094. [CrossRef]

20. He, H.; Guo, J.; Lin, X.; Xu, B. Enzyme-Instructed Assemblies Enable Mitochondria Localization of Histone H2B in Cancer Cells. Angew. Chem. Int. Ed. 2020, 59, 9330-9334. [CrossRef]

21. Feng, Z.; Han, X.; Wang, H.; Tang, T.; Xu, B. Enzyme-Instructed Peptide Assemblies Selectively Inhibit Bone Tumors. Chem 2019, 5, 2442-2449. [CrossRef]

22. Yang, Z.; Liang, G.; Wang, L.; Xu, B. Using a kinase/phosphatase switch to regulate a supramolecular hydrogel and forming the supramolecular hydrogel in vivo. J. Am. Chem. Soc. 2006, 128, 3038-3043. [CrossRef]

23. Gao, J.; Zheng, W.; Kong, D.; Yang, Z. Dual enzymes regulate the molecular self-assembly of tetra-peptide derivatives. Soft Matter 2011, 7, 10443-10448. [CrossRef]

24. Collier, J.H.; Messersmith, P.B. Enzymatic Modification of Self-Assembled Peptide Structures with Tissue Transglutaminase. Bioconjug. Chem. 2003, 14, 748-755. [CrossRef] [PubMed]

25. Wakabayashi, R.; Suehiro, A.; Goto, M.; Kamiya, N. Designer aromatic peptide amphiphiles for self-assembly and enzymatic display of proteins with morphology control. Chem. Commun. 2019, 55, 640-643. [CrossRef] [PubMed]

26. Ohshima, T.; Sakono, M. Enzymatic Installation of Functional Molecules on Amyloid-Based Polymers. Bioconjug. Chem. 2017, 28, 2687-2691. [CrossRef] [PubMed]

27. Varland, S.; Vandekerckhove, J.; Drazic, A. Actin Post-translational Modifications: The Cinderella of Cytoskeletal Control. Trends Biochem. Sci. 2019, 44, 502-516. [CrossRef]

28. Song, Y.; Brady, S.T. Post-translational modifications of tubulin: Pathways to functional diversity of microtubules. Trends Cell Biol. 2015, 25, 125-136. [CrossRef] [PubMed]

29. Strop, P. Versatility of Microbial Transglutaminase. Bioconjug. Chem. 2014, 25, 855-862. [CrossRef]

30. Popp, M.W.L.; Ploegh, H.L. Making and breaking peptide bonds: Protein engineering using sortase. Angew. Chem. Int. Ed. 2011, 50, 5024-5032. [CrossRef] [PubMed]

31. Tang, C.; Ulijn, R.V.; Saiani, A. Effect of glycine substitution on Fmoc-diphenylalanine self-assembly and gelation properties. Langmuir 2011, 27, 14438-14449. [CrossRef] [PubMed]

32. Folk, J.E.; Cole, P.W. Mechanism of Action of Guinea Pig Liver Transglutaminase. J. Biol. Chem. 1966, 241, 5518-5525. [CrossRef]

33. Kubota, R.; Nakamura, K.; Torigoe, S.; Hamachi, I. The Power of Confocal Laser Scanning Microscopy in Supramolecular Chemistry: In situ Real-time Imaging of Stimuli-Responsive Multicomponent Supramolecular Hydrogels. Chem. Open 2020, 9 , 67-79. [CrossRef] [PubMed]

34. Sato, R.; Minamihata, K.; Ariyoshi, R.; Taniguchi, H.; Kamiya, N. Recombinant production of active microbial transglutaminase in E. coli by using self-cleavable zymogen with mutated propeptide. Protein Expr. Purif. 2020, 176, 105730. [CrossRef] [PubMed] 